\title{
2.5次元境界要素法を用いた堆積盆地の地震動増幅特性解析 GROUND MOTION AMPLIFICATION ANALYSIS OF SEDIMENTARY BASIN BASED ON 2.5D BEM
}

\author{
篠崎 祐三*1, 引野 剛*2 \\ Yuzo SHINOZAKI and Tsuyoshi HIKINO
}

\begin{abstract}
A direct 2.5 dimensional boundary element method is applied to evaluate ground motions in twodimensional sedimentary basin due to a three-dimensional Haskell-type fault to estimate the amplification characteristics of the ground motions in the heavily damaged belt zone in Kobe City during the 1995 Hyogo-ken earthquake. We have utilized the Green's functions for an elastic half-space medium to formulate boundary integral equations in terms of displacements and tractions at the medium interface. The effects of different types of cross-section of the sedimentary basin on the strong gound motions in the basin are examined in detail.
\end{abstract}

Keywords: Ground motion; sedimentary basin; boundary element method; Kobe earthquake; heavily damaged belt zone

強震動、不整形堆積盆地、境界要素法、兵庫県南部地震、「震災の帯」

1. はじめに

1995 年兵庫県南部地震において生じた震度 7 (激震) の 地域（震災の帯）は、神戸市須磨区から西宮市にかけて長 さ約 $20 \mathrm{~km}$ 、幅 $1 \mathrm{~km}$ で帯状に広がっている。地震後の地 下構造探査により、六甲山から海側への基盤構造が深さ約 $1 \mathrm{~km}$ 程度の段差のある深い不整形地盤構造 ${ }^{1)}$ であること と、東西に長い「震災の帯」が不整形地盤端部に位置して いることが判明した。建築物、特に木造家屋の被災状況か ら特定された「震災の帯」内では強震動がほとんど記録さ れていないが、地動増幅度分布と「震災の帯」の建物被害 分布が直結しているという予想の下に、深い不整形地盤域 の強震動シミュレーションが 2 次元 $\mathrm{FEM}^{2}$ 、薄層法 ${ }^{3)}$ 、有 限差分 ${ }^{4,5)}$ 、3 次元境界要素法 ${ }^{6)}$ などの解析法に基づき行 なわれてきた。本研究では、2次元不整形堆積盆地モデル を設定し、盆地端部に配置させた 3 次元断層震源より射出 する入力地震動による堆積盆地の地動応答を、いわゆる 2 . 5 次元境界要素法により評価する。2.5 次元境界要素法 を用いた主な理由として、1)FEM や FDM のように人工 境界を設定する必要がない。2) 境界線上の境界積分方程式 を解析するので、3 次元 BEM より記憶容量が少なくて済 む。3) 地動応答に及ぼす断層震源の特性を分離して評価可 能である 7)。4) 任意形状の地層境界をもつ不整形地盤モデ ルに対して解析可能である、等を挙げることができる。本 研究は簡易な 3 次元移動断層震源モデルと 2 次元堆積盆地 モデルを設定し、盆地地震動分布に及ぼす盆地端部の形状 の影響を検討し、「震災の帯」の出現要因に関して定性的
考察を加えたものである。

2. モデルと解析方法
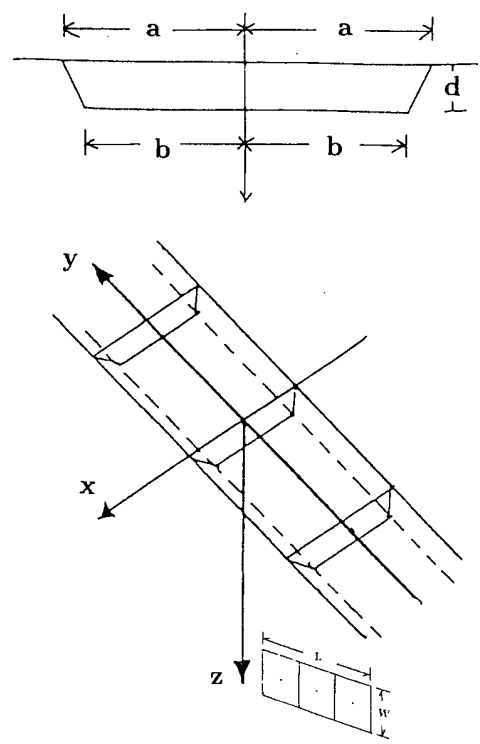

図 1. 解析モデル

解析モデルは図 1 に示すように地層境界が任意形状をな す 2 次元堆積盆地である。地盤構造は 2 次元であるが、 3 次元入射波動場を想定するため、調和波動応答を 2.5 次
*1 東京理科大学工学部建築学科 教授. 工博

*2 新日本製鉄建築事業部 工修
Prof., Dept. of Architecture, Science University of Tokyo, Dr. Eng. Shin-Nippon Steel Co., M. Eng. 
元境界要素法で解析し、FFTにより時刻歴応答を評価す る7)。

次式に示すように堆積盆地の地層境界線 $\Gamma(\mathrm{y}=0)$ に対 する境界条件に関してのみ境界積分方程式を定式化すれば よい。

$$
\begin{gathered}
\frac{1}{2} \cdot \tilde{u}_{i}^{(2)}\left(\mathbf{x}^{*}\right)-\int_{\Gamma}\left\{\tilde{G}_{j i}^{(2)}\left(\mathbf{x} ; \mathbf{x}^{*}\right) \cdot \tilde{p}_{j}^{(2)}(\mathbf{x}, \mathbf{n})\right. \\
\left.-\tilde{H}_{j i}^{(2)}\left(\mathbf{x}, \mathbf{n} ; \mathbf{x}^{*}\right) \cdot \tilde{u}_{j}^{(2)}(\mathbf{x})\right\} d \Gamma=\tilde{u}_{i}^{i n c}\left(\mathbf{x}^{*}\right) \\
\frac{1}{2} \cdot \tilde{u}_{i}^{(1)}\left(\mathbf{x}^{*}\right)+\int_{\Gamma}\left\{\tilde{G}_{j i}^{(1)}\left(\mathbf{x} ; \mathbf{x}^{*}\right) \cdot \tilde{p}_{j}^{(1)}(\mathbf{x}, \mathbf{n})\right. \\
\left.-\tilde{H}_{j i}^{(1)}\left(\mathbf{x}, \mathbf{n} ; \mathbf{x}^{*}\right) \cdot \tilde{u}_{j}^{(1)}(\mathbf{x})\right\} d \Gamma=0
\end{gathered}
$$

上式で $\tilde{u}_{i}^{(1)}\left(\mathbf{x}^{*}\right)$ などの上添字は地盤媒質を示す。すなわち、 （1）は盆地地盤を、(2) は盆地外の半無限地盤を表す。

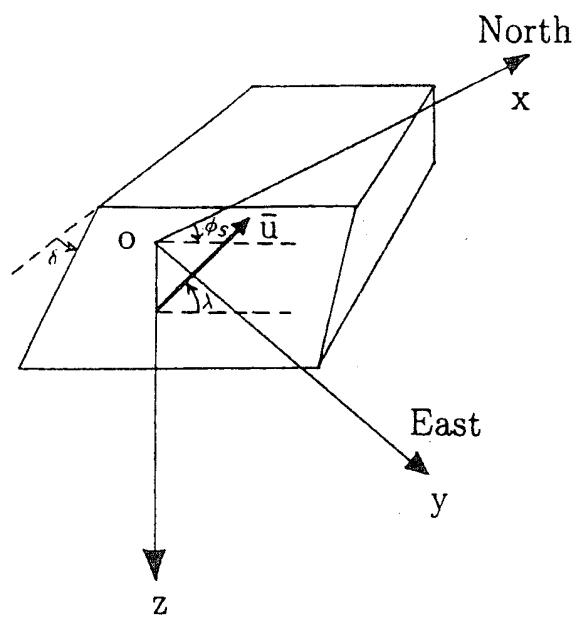

図 2. 断層モデル

地層境界線 $\Gamma(\mathrm{y}=0)$ での変位、応力の連続の境界条件を 導入し、(1) 式の連立境界積分方程式を数值解析する。入力 項 $u_{i}^{i n c}\left(\mathrm{x}^{*}\right)$ の計算は入射波動場に応じて評価するが、移動 断層震源を考慮する場合、次式から求めた Double couple による変位場を重ね合わせて計算する ${ }^{8)}$ 。

$$
\tilde{u}_{i}^{i n c}\left(\mathbf{x}^{*}\right)=M_{j k} \cdot \tilde{G}_{i j, k}
$$

ここで、 $M_{j k}$ は地震モーメントテンソルであり、 $\tilde{G}_{i j, k}$ は グリーン関数 $\tilde{G}_{i j}$ の $k$ 成分での微分を表す。上式から分か るように断層震源から射出する波動場の $\mathrm{SH}$ 成分や $\mathrm{P}-\mathrm{SV}$ 成分を分離ができて、地動応答に及ぼす成分の影響を詳細

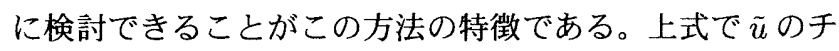
ルダは、y軸方向に対するフーリエ変換を意味する。すな わち、以下のように書ける。

$$
\begin{gathered}
\tilde{u}_{j}\left(\omega ; x, k_{y}, z\right)=\int_{-\infty}^{\infty} u_{j}(\omega ; x, y, z) e^{i k_{y} y} d y \\
\tilde{p}_{j}\left(\omega ; x, k_{y}, z^{\prime}, \mathbf{n}\right)=\int_{-\infty}^{\infty} p_{j}\left(\omega ; x, y, z^{\prime}, \mathbf{n}\right) e^{i k_{y} y} d y
\end{gathered}
$$

$\tilde{G}_{j i}\left(\omega ; x^{\prime}, k_{y}, z^{\prime} ; x, 0, z\right)=$

$$
\begin{gathered}
\int_{-\infty}^{\infty} G_{j i}\left(\omega ; x^{\prime}, y^{\prime}, z^{\prime} ; x, 0, z\right) e^{i k_{y} y^{\prime}} d y^{\prime} \\
\tilde{H}_{j i}\left(\omega ; x^{\prime}, k_{y}, z^{\prime}, \mathbf{n} ; x, 0, z\right)= \\
\int_{-\infty}^{\infty} H_{j i}\left(\omega ; x^{\prime}, y^{\prime}, z^{\prime}, \mathbf{n} ; x, 0, z\right) e^{i k_{y} y^{\prime}} d y^{\prime}
\end{gathered}
$$

断層の記号パラメータの定義を図 2 に示す。すなわち、 断層の走向 $\phi_{s}$ 、傾斜角 $\delta 、$ すへり方向 $\lambda$ である。すべりの 矢印は上盤（図には描かれていない）の下盤（図に描かれ ている）に対する相対運動の方向である。なお、具体的な 計算手順については Appendix を参照のこと。

\section{3. 数值解析結果}

3 次元断層震源を地中（ $\mathrm{y}=0 ）$ の位置に配置させた場合 の 2 次元不整形堆積盆地の $125 \mathrm{~m}$ 間隔の 78 地点の盆地地 動時刻歴応答を示す。同時に各地点の最大応答值の大きさ をシンボル ৩までの時間軸長さに換算して示した。その 際、全応答值の最大のものを 40sec になるように基準化し た。なお、以下の計算では境界要素法の要素分割を増やし、 計算精度を検証している。最大要素長さを的 $142 \mathrm{~m}$ として いる。盆地内地盤の最低速地震波速度は $\mathrm{S}$ 波 $1.575 \mathrm{~km} / \mathrm{sec}$ であるので約 $1.5 \mathrm{~Hz}$ 程度まで十分な精度を持つと考えら れる。
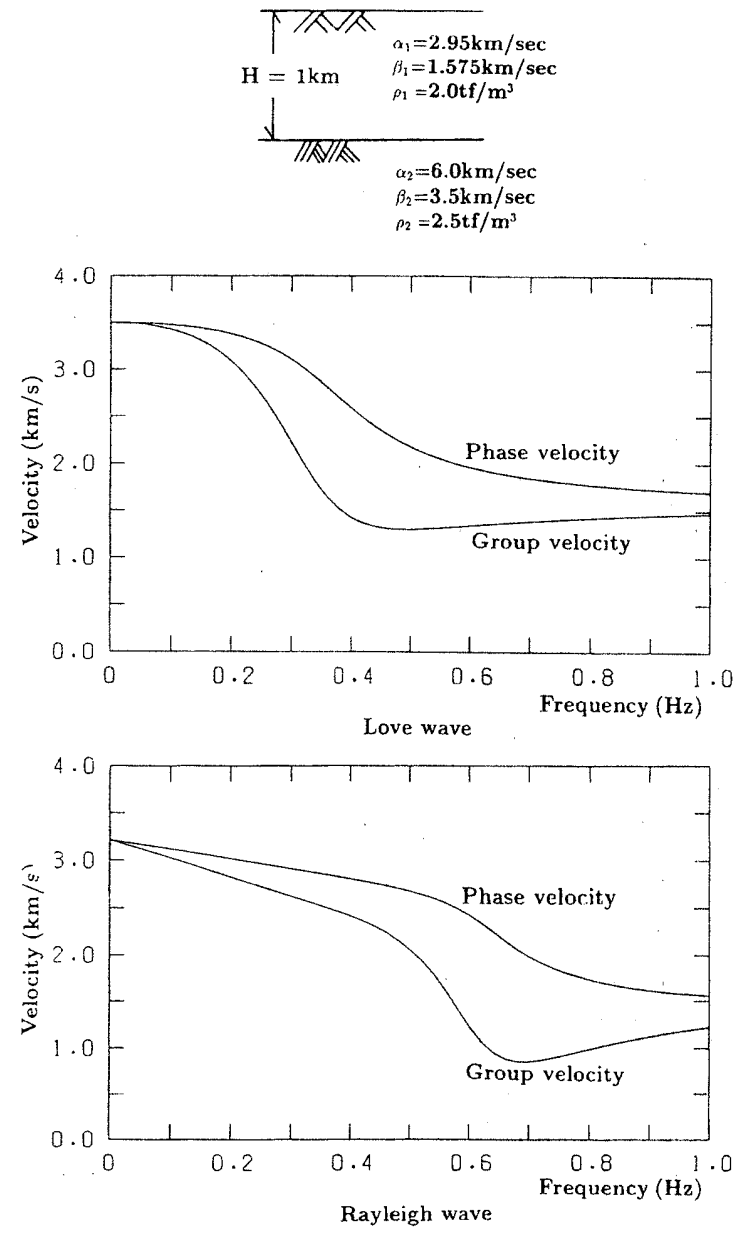

図 3. 分散曲線

堆積盆地の地表面での半幅 $\mathrm{a}=5.0 \mathrm{~km}$ 、層厚 $\mathrm{d}=1.0 \mathrm{~km}$ の堆積盆地である。盆地両端の地層傾斜角度の強震地動へ 

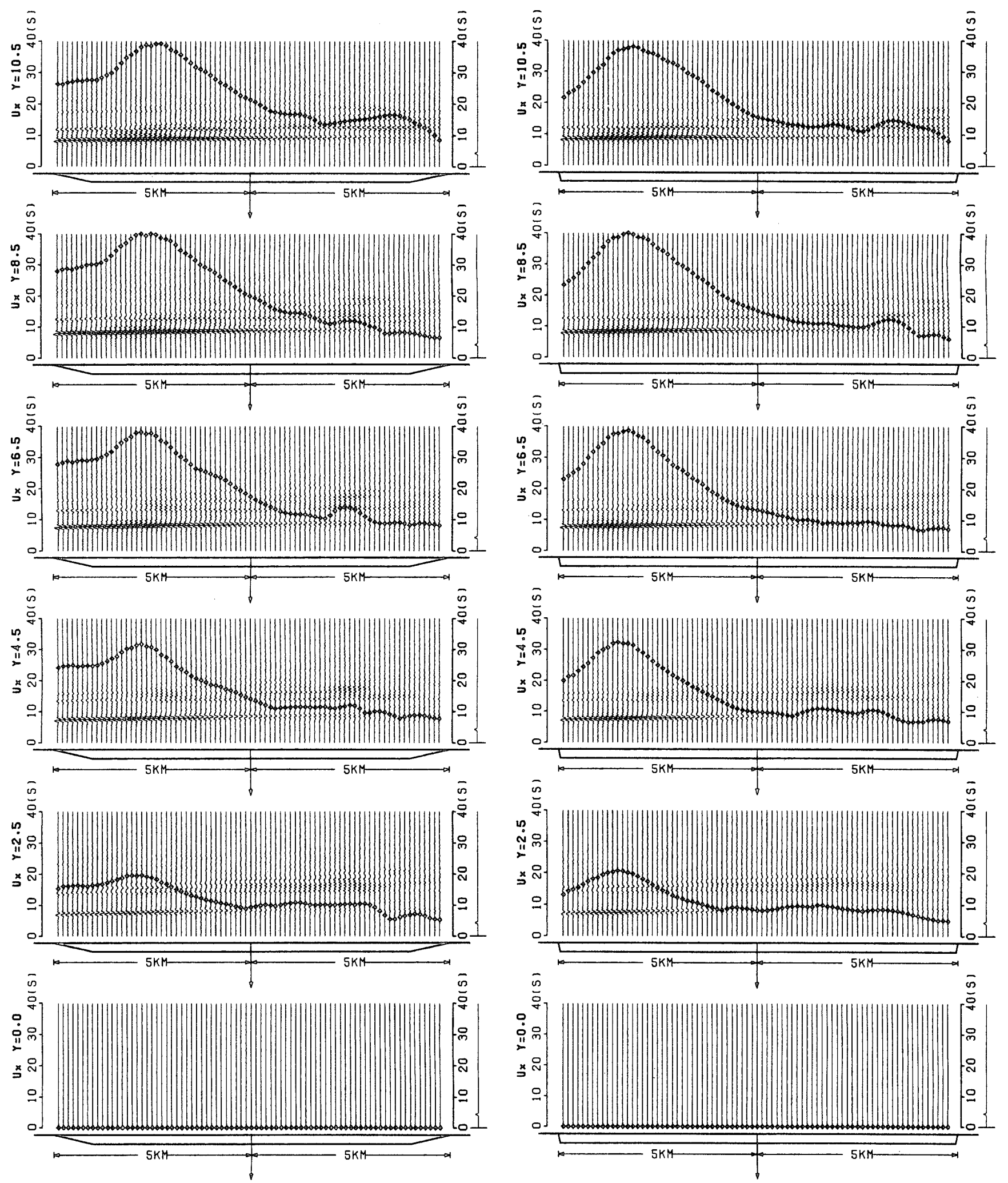

図 4A. 盆地モデル $\mathrm{A}$ の地動速度応答 $\mathrm{Ux}$

図 4B. 盆地モデル B の地動速度応答 $\mathrm{Ux}$ 
の影響を調べるため、以下の時刻歴応答の下に盆地断面図 を示すように、盆地の大部分は成層地盤であるが、盆地の 端部の形状が、モデル A : 傾斜地層境界が $45^{\circ}$ をなす台形 型、モテル B : 盆地底部ではほぼ直角の直角型、モデル C : 傾斜地層境界が $135^{\circ}$ の逆台形型の 3 つのモデルを想定し た。なお、神戸市の「震災の帯」近傍の地下構造探査によ れば、モデル A とモデル C を組み合わせた “逆くの字”型 の断層境界も報告されている ${ }^{1)}$ 。

盆地内地盤の $\mathrm{S}$ 波速度を $\beta_{1}=1.575 \mathrm{~km} / \mathrm{sec}$ に、盆地外地 盤の $\mathrm{S}$ 波速度を $\beta_{2}=3.5 \mathrm{~km} / \mathrm{sec}$ に、ポアソン比を、それぞ れ $\nu_{1}=0.3, \nu_{2}=0.24$ に想定した。この地首構成の水平成 首地盤（図 3 上のモテル）の Love 波と Rayleigh 波の分散 曲線を図 3 に示す。

2 次元堆積盆地に対する点震源としての断層震源による 地震動入射の場合の応答例を図 4 に示す。盆地地首境界が $45^{\circ}$ （モデル A）の場合とほぼ直角の場合（モデル B）を 示す。地中 $(x=+6 \mathrm{~km}, y=0 \mathrm{~km}, z=+10 \mathrm{~km})$ で右横ず れ断首 (断層の走向 $\phi_{s}=90^{\circ}$ 、傾斜角 $\delta=90^{\circ}$ 、すべり方 向 $\lambda=180^{\circ}$ 、Rise time $\left.=1 \mathrm{sec}\right)$ を想定した場合の堆積盆
地上 $\mathrm{y}=0 \mathrm{~km}, 2.5 \mathrm{~km}$ から $2 \mathrm{~km}$ 間隔の 5 側線上の盆地地層 境界直近の $\mathrm{x}=+4.875 \mathrm{~km}$ から $125 \mathrm{~m}$ 間隔の 78 地点の断首 直交方向地動速度応答 (Fault normal component) $u_{x}$ 成分 を示す（いずれも最下段の図が震源に最も近い地点の応答 である)。

断首の配置と地層構造の関係から $\mathrm{y}=0 \mathrm{~km}$ 上では断層直 交方向成分 $u_{x}$ 、及び上下動成分 $u_{z}$ は零であるが、断屏平 行成分 $u_{y}$ の地動速度応答のみが生ずる。しかし、震源（ $\mathrm{x}$ 軸）から離れるに従い、断層直交方向成分の応答は增幅し 始め、この場合では、 $\mathrm{y}=8.5 \mathrm{~km}$ の測線上で最大応答を示 す。盆地端部に近い地点では、盆地のない一様半無限地盤 の場合では応答は増幅する地点であるが、硬質地盤の拘束 効果のため応答は小さく、盆地の内側の地点になるに従い 応答は増幅し、ピークに達したのち減衰する。傾斜地層境 界がほぼ直角な図 $4 \mathrm{~B}$ の場合では盆地側約 $1.75 \mathrm{~km}$ の地点 で最大応答を示すのに対し、傾斜地層境界が $45^{\circ}$ の図 $4 \mathrm{~A}$ の場合では約 $2.375 \mathrm{~km}$ の地点、すなわち、モデル Bより 約 $625 \mathrm{~m}$ も盆地内側で生じている。この図に示されるよう に後続位相が小さく表面波の影響は小さい。地盤構造は 2

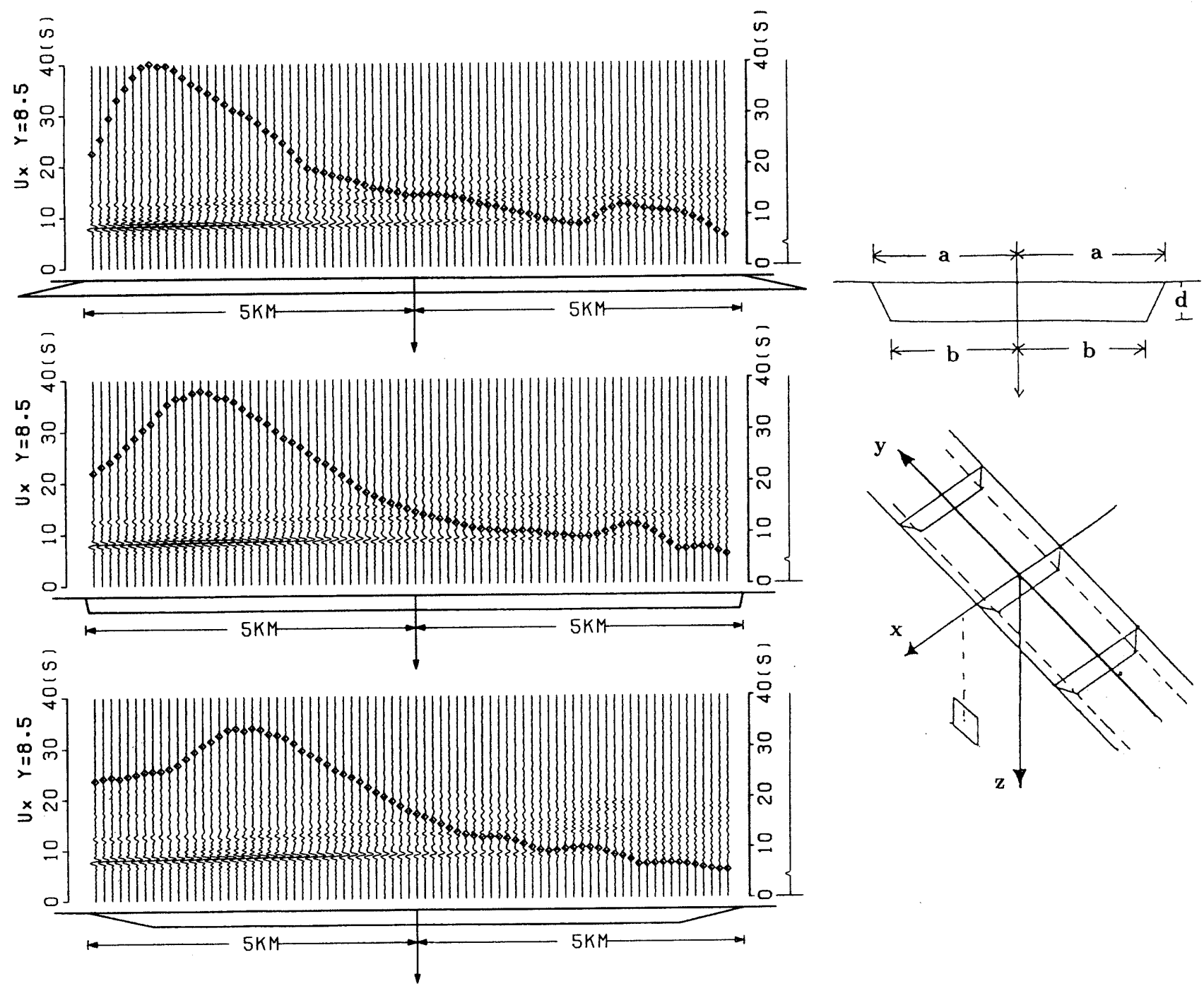

図 5. 各盆地モデルの地動速度応答 $\mathrm{Ux}$ 

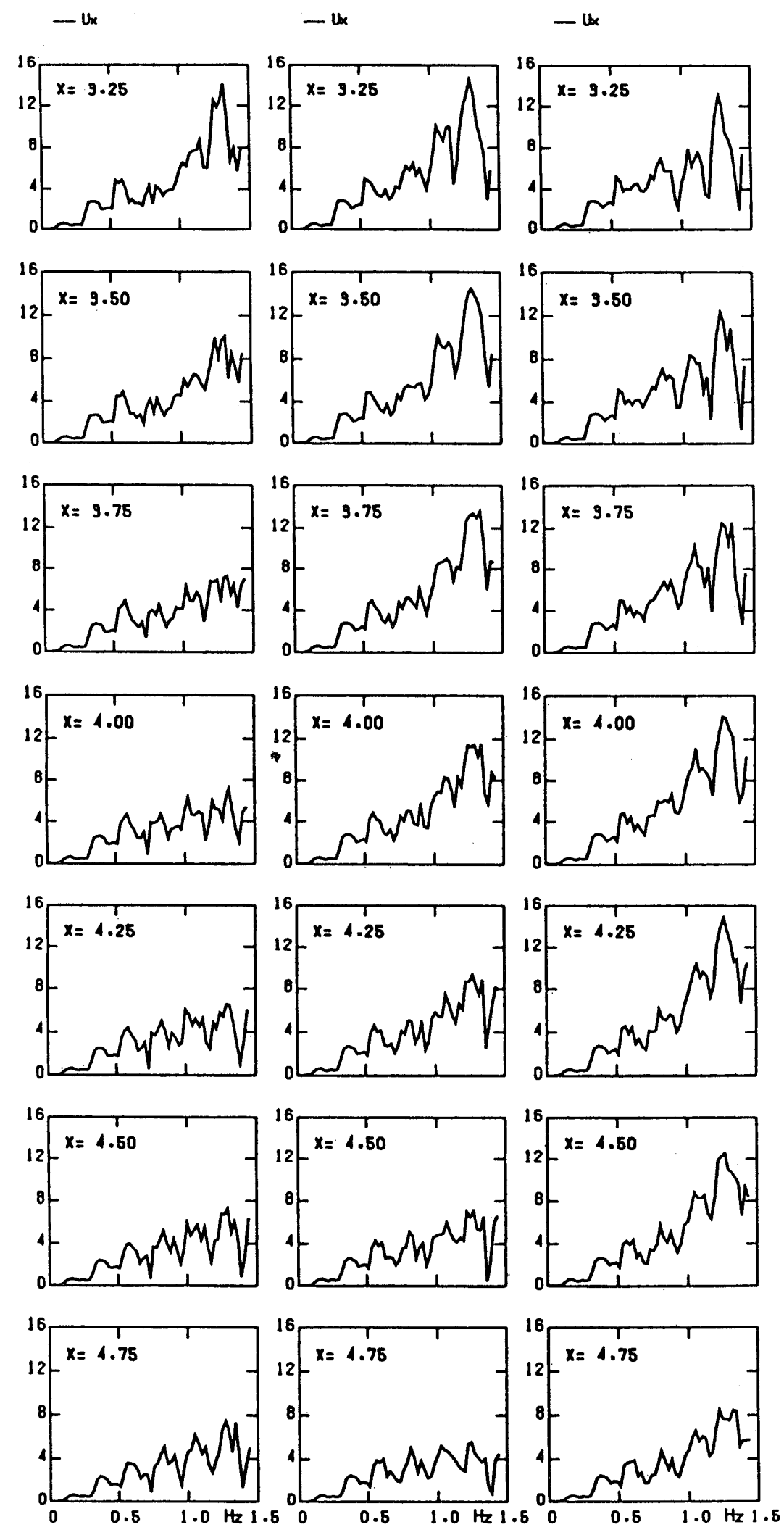

モデル A

モデル B

モデル $\mathrm{C}$

図 6. 各盆地モデルの周波数応答倍率 $\mathrm{Ux}(\mathrm{y}=8.5 \mathrm{~km})$ 
次元であるが、傾斜地層境界に入射する地震動は球面波で あるため、y 軸に対して直交方向に伝播する表面波成分は 小さいと考えられるのである。

盆地地層境界の形状の差異が盆地地動速度応答 $(\mathrm{y}=8.5 \mathrm{~km}$ の測線上) に及ぼす影響を図 5 に示す。断層パラメー夕等 は図 4 の結果と同一である。断層直交方向応答 $u_{x}$ の最大 応答值は、傾斜地層境界が逆台形型、直角型、台形型の順 序で小さくなり、また、その最大応答値を示す地点は、そ の順序で盆地地層境界に近い位置で起こり、盆地内側での 応答値の減衰性状も鈍化する。

逆台形型盆地のモデル C の最大応答值はモデル A のそれ より約 $20 \%$ 増幅し、その最大応答值を示す地点は約 $1.25 \mathrm{~km}$ も離れていて、盆地端部境界形状の影響が大きいことが分 かる。以上のような盆地端部近傍の応答特性は断層震源の 位置、地層境界のサイズ、及び地盤間の波動インピーダン ス比と入射波動の波長の相対関係に依存するものであり、 より周期の長い入射波動の場合には、盆地端部のサイズが
入射波動の波長に比べ小さいので、これほどの差異は生じ ない。このことは、各モデルの端部近傍の断層直交方向成 分 $u_{x}$ の周波数応答倍率を示す図 6 からも分かる。同図は $1.5 \mathrm{~Hz}$ までの各モデルの $(\mathrm{y}=8.5 \mathrm{~km}, \mathrm{x}=4.75 \mathrm{~km} \sim 3.25 \mathrm{~km})$ の 7 地点の応答倍率を示すものである。約 $0.5 \mathrm{~Hz}$ 位まで は、各モデル間の応答倍率の差異は小さいが、図 5 で示し た $1 \mathrm{~Hz}$ 近傍では $\mathrm{x}=4 \mathrm{~km}$ のモデル $\mathrm{C}$ と $\mathrm{A}$ とでは 2 倍位の 差があること、また、さらに高振動数域では $\mathrm{x}=3.25 \mathrm{~km}$ で はモデル A がモデル C の底答を越えることもあることが 分かる。

図 7 は盆地の無い場合の半無限弾性地盤の移動断層震源 による地動速度応答 $(\mathrm{y}=0, \mathrm{x}=+4.875 \mathrm{~km}$ から $125 \mathrm{~m}$ 間 隔の 78 地点) を示す。

移動断層震源の諸元として、 $(\mathrm{x}=6 \mathrm{~km},-13.5 \mathrm{~km} \leq \mathrm{y} \leq$ $-7.5 \mathrm{~km}, 9 \mathrm{~km} \leq \mathrm{z} \leq 11 \mathrm{~km})$ の矩形領域を $2 \mathrm{~km} \times 2 \mathrm{~km}$ の 3 つの要素に分けて、断層の走向 $\phi_{s}=90^{\circ}$ 、傾斜角 $\delta=90^{\circ}$ 、 すべり方向 $\lambda=180^{\circ}$ 、震源時間関数として正弦波半波 (Rise

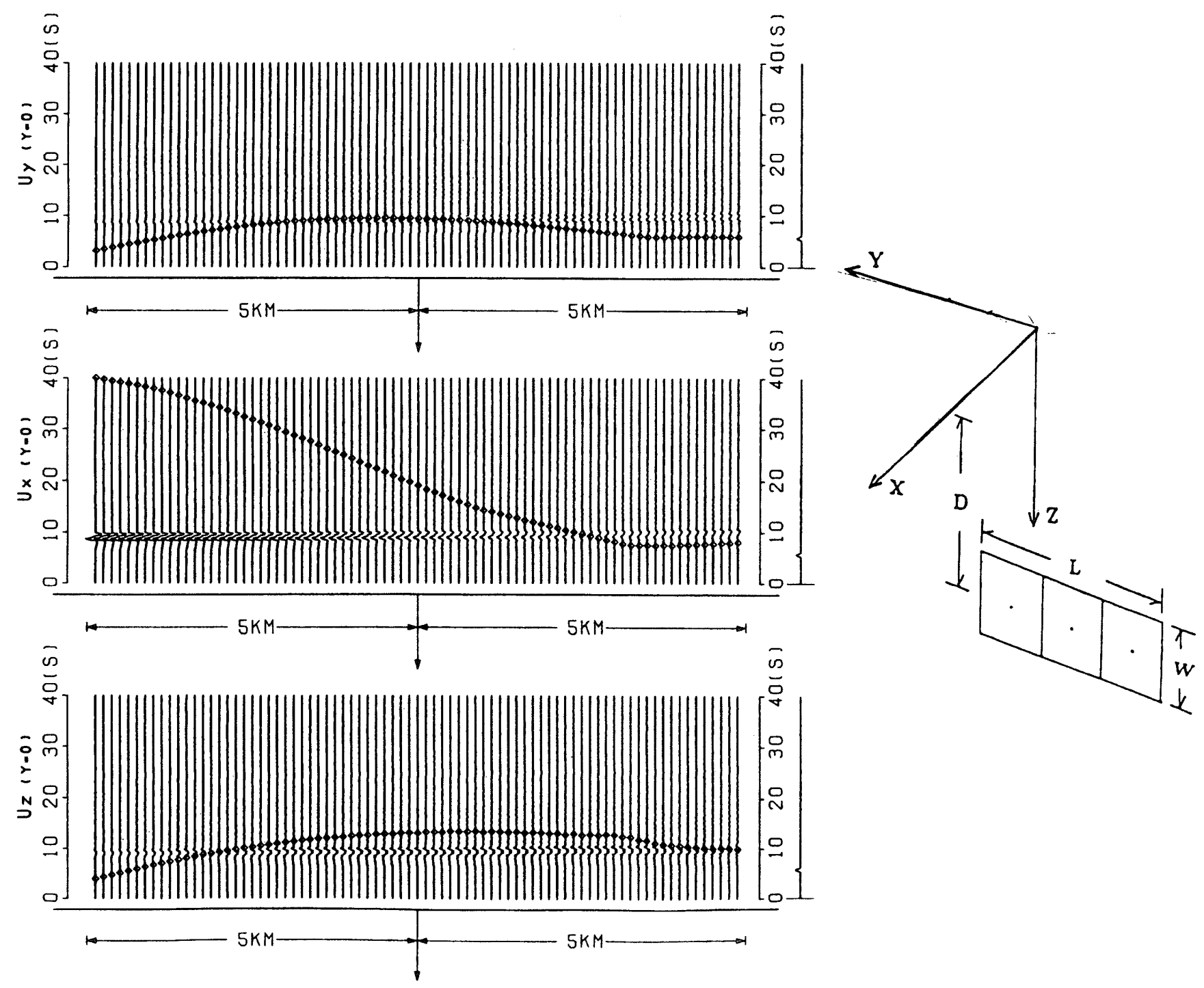

図 7. 移動断層震源による半無限弾性地盤の地動速度応答 


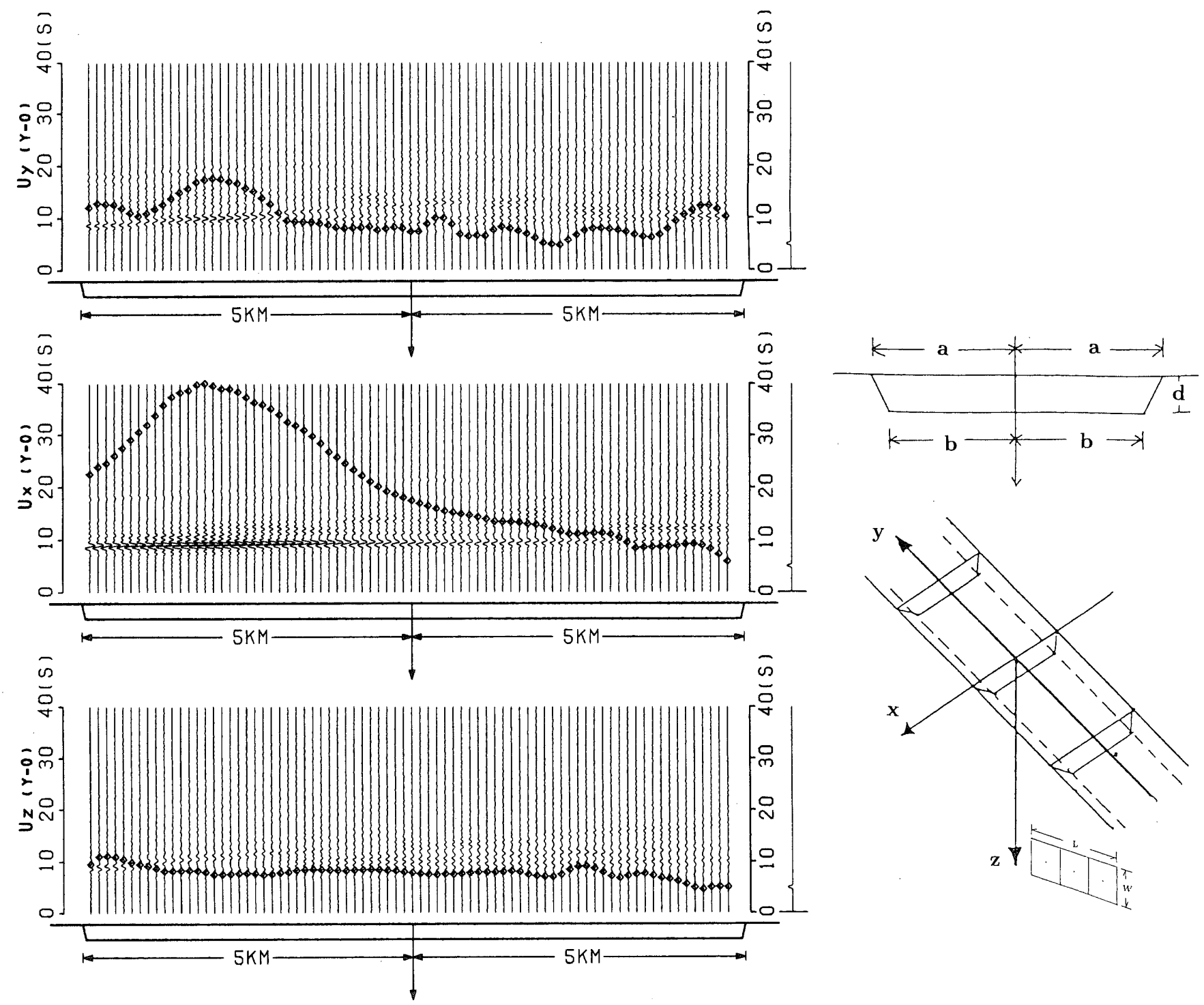

図 8. 移動断層震源によるモデル B 盆地の地動速度応答

time $=1 \mathrm{sec}) 、$ Rupture velocity $=2.8 \mathrm{~km} / \mathrm{sec}$ を仮定した。

断層震源の Radiation pattern と断層の破壊方向への directivity 効果により、断層直交方向成分 $u_{x}$ が卓越し、他 の 2 成分より最大值で 2 倍以上の差があり、断層面延長線 から離れるに従い、徐々に減衰する。

図 8 は前図と同一の移動断層震源による 2 次元盆地の地 動速度応答 $(\mathrm{y}=0, \mathrm{x}=+4.875 \mathrm{~km}$ から $125 \mathrm{~m}$ 間隔の 78 地 点) を示す。半無限弾性地盤の場合では最も増幅していた 断層面延長線では盆地地層境界近傍で硬質地盤側の拘束効 果により増幅しないが、地層境界より離れるに従い増幅し 始め盆地地層境界より約 $2.5 \mathrm{~km}$ 程離れた地点でピークを 示し、以後急激に減衰し、このような単純な地盤構造モデ ルでも「震災の帯」を再現していると考えられる。

\section{4. 結び}

2 次元盆地端部近傍に 3 次元断層震源を配置し、盆地の 地動底答を 2.5 次元境界要素法を用いて解析した。
移動断層震源による 2 次元盆地の地動速度応答を評価し、 単純な地盤構造モデルでも、1995 年兵庫県南部地震で 生じた「震災の帯」をある程度再現できることを示した。

盆地端部断面形状をモデル A : 傾斜地層境界が $45^{\circ}$ をな す台形型、モデル B : 盆地底部ではほぼ直角の直角型、モ デル C : 傾斜地層境界が $135^{\circ}$ の逆台形型の 3 つのモデル を想定した。設定したモデルに対する数值解析結果から、 盆地内強震地動分布に及ぼす盆地端部形状の影響は、盆地 端部サイズより長い入射波長の長周期地震動の場合小さい が、短周期領域で顕著であり、最大応答值が 3 者のモデル 間で、それぞれ、約 $600 \mathrm{~m}$ も離れた地点で生ずる場合もあ ることを明らかにした。

謝辞

本研究を実施するうえで藤原広行博士 (防災科学技術研 究所), 堀家正則博士 (大阪工業大学) にご協力を、また、 財団法人 鹿島学術振興財団研究助成金の援助を受けまし 
た。ここに記して感謝申し上げます。

\section{参考文献}

1) 岩田 (1995) 強震動と地盤構造、第 23 回地盤震動シン ポジウム、1995 年兵庫県南部地震で試された地盤震 動研究、日本建築学会、29-38.

2) Kawase(1996)The cause of the damage belt in Kobe: "The basin-edge effect", Constructive interference of the direct S-wave with the basin-induced diffracted/Rayleigh waves, Seismological Research Letters, 67, No.5, 25-34.

3) 源栄、永野 (1996) 深部不整形地下構造を考慮した神 戸市の地震動の増幅特性解析 - 兵庫県南部地震にお ける「震災の帯」の解釈-日本建築学会構造系論文集、 No. $488,39-48$.

4) Pitarka, A., K. Irikura, T. Iwata, and T. Kagawa(1996) Basin structure effects in the Kobe area inferred from the modeling of ground motions from two aftershocks of the January 17, 1995, Hyogokennanbu earthquake, J. Phys. Earth. 44, 563-576.

5) 川瀬、松島 (1998) 三次元盆地構造を考慮した 199 5 年兵庫県南部地震の神戸地域における強震動シミュ レーション、日本建築学会構造系論文集、No. 514, 111-118.

6) 篠崎、吉田 (1998) 兵庫県南部地震「震災の帯」発生 要因に関する考察 : 震源と盆地の影響、第 10 回日本 地震工学シンポジウム論文集、731-736.

7) Fujiwara(1996) Three-dimensional wavefield in a two-dimensional basin structure due to point source, J. Phys. Earth., 44, 1-22.

8) Aki \& Richards(1980) Quantitative Seismology. Theory and Methods, W. H. Freeman and Company, San Francisco, p.114.

9) Bouchon, M. and K. Aki(1977) Discrete wavenumber representation of seismic-source wave fields, Bull. Seism. Soc. Am., 67, 259-277.

\section{Appendix}

2.5 次元半無限弾性地盤のグリーン関数の一成分（ $\mathrm{x}$ 軸 方向加振で、 $\mathrm{x}$ 軸方向変位 $) \tilde{G}_{x x}^{H}\left(\mathbf{x} ; \mathbf{x}^{*}\right)$ を次に示す。右辺 第 $1 、 2$ 項は全無限弾性地盤のグリーン関数とその鏡像で あり、(A2) 式に示される。

$$
\begin{aligned}
& \tilde{G}_{x x}^{H}\left(\mathbf{x} ; \mathbf{x}^{*}\right)=\tilde{G}_{x x}^{F}\left(\mathbf{x} ; \mathbf{x}^{*}\right)+\tilde{G}_{x x}^{F}\left(\mathbf{x} ; \overline{\mathbf{x}}^{*}\right) \\
& -\frac{i}{2 \pi \mu k_{\beta}^{2}} \int_{0}^{\infty} \frac{P\left(z_{p}\right) \cdot P\left(z_{s}\right)}{\nu_{\alpha} F_{R}} \cdot 2 k_{x}^{2} \cos \left[\left(x_{p}-x_{s}\right) k_{x}\right] d k_{x} \\
& \quad P(z)=\left[2\left(k_{x}^{2}+k_{y}^{2}\right)-k_{\beta}^{2}\right] e^{-i \nu_{\alpha} z}+2 \nu_{\alpha} \nu_{\beta} e^{-i \nu_{\beta} z} \\
& \quad F_{R}=\left[2\left(k_{x}^{2}+k_{y}^{2}\right)-k_{\beta}^{2}\right]^{2}+4\left(k_{x}^{2}+k_{y}^{2}\right) \nu_{\alpha} \nu_{\beta} \\
& \quad \mathbf{x}=\left(x, k_{y}, z\right) \\
& \overline{\mathbf{x}}=\left(x, k_{y},-z\right)
\end{aligned}
$$

$$
\begin{aligned}
& \tilde{G}_{x x}^{F}\left(\mathbf{x} ; \mathbf{x}^{*}\right)=-\frac{i}{4 \mu} Z_{0}\left(\nu_{\beta} r\right)+\frac{i}{4 \mu k_{\beta}^{2}} \cdot \frac{1}{r}\left[\nu_{\beta} Z_{1}\left(\nu_{\beta} r\right)-\nu_{\alpha} Z_{1}\left(\nu_{\alpha} r\right)\right] \\
& +\frac{i}{4 \mu k_{\beta}^{2}} \cdot \frac{\left(x_{p}-x_{s}\right)^{2}}{r^{2}}\left[\nu_{\beta}^{2} Z_{2}\left(\nu_{\beta} r\right)-\nu_{\alpha}^{2} Z_{2}\left(\nu_{\alpha} r\right)\right] \\
& \nu_{\alpha}= \begin{cases}\sqrt{k_{\alpha}^{2}-k_{y}^{2}} & \text { for }\left|k_{y}\right| \leq k_{\alpha} \\
-i \sqrt{k_{y}^{2}-k_{\alpha}^{2}} & \text { for }\left|k_{y}\right|>k_{\alpha}\end{cases} \\
& \nu_{\beta}= \begin{cases}\sqrt{k_{\beta}^{2}-k_{y}^{2}} & \text { for }\left|k_{y}\right| \leq k_{\beta} \\
-i \sqrt{k_{y}^{2}-k_{\beta}^{2}} & \text { for }\left|k_{y}\right|>k_{\beta}\end{cases} \\
& Z_{1}\left(\nu_{\alpha} r\right)= \begin{cases}H_{1}^{(2)}\left(\nu_{\alpha} r\right) & \text { for }\left|k_{y}\right| \leq k_{\alpha} \\
-\frac{2 i}{\pi} K_{1}\left(i \nu_{\alpha} r\right) & \text { for }\left|k_{y}\right|>k_{\alpha}\end{cases} \\
& Z_{1}\left(\nu_{\beta} r\right)= \begin{cases}H_{1}^{(2)}\left(\nu_{\beta} r\right) & \text { for }\left|k_{y}\right| \leq k_{\beta} \\
-\frac{2 i}{\pi} K_{1}\left(i \nu_{\beta} r\right) & \text { for }\left|k_{y}\right|>k_{\beta}\end{cases} \\
& Z_{2}\left(\nu_{\alpha} r\right)= \begin{cases}H_{2}^{(2)}\left(\nu_{\alpha} r\right) & \text { for }\left|k_{y}\right| \leq k_{\alpha} \\
-\frac{2 i}{\pi} K_{2}\left(i \nu_{\alpha} r\right) & \text { for }\left|k_{y}\right|>k_{\alpha}\end{cases} \\
& Z_{2}\left(\nu_{\beta} r\right)= \begin{cases}H_{2}^{(2)}\left(\nu_{\beta} r\right) & \text { for }\left|k_{y}\right| \leq k_{\beta} \\
-\frac{2 i}{\pi} K_{2}\left(i \nu_{\beta} r\right) & \text { for }\left|k_{y}\right|>k_{\beta}\end{cases}
\end{aligned}
$$

上式で、 $k_{\alpha}=\omega / \alpha, k_{\beta}=\omega / \beta$ であり、 $\alpha, \beta, \mu$ は、それ ぞれ、地盤の $\mathrm{P}$ 波速度、 $\mathrm{S}$ 波速度、せん断剛性率である。 また、 $H_{1}^{(j)}(\bullet) や 、 K_{j}(\bullet),(j=1,2)$ は、それぞれハンケ ル関数と変形ベッセル関数である。

\section{- 2.5 次元問題の応答計算手順}

1) 設定振動数 $(\omega), y$ 方向波数 $\left(k_{y}\right)$ ごとの地層境界 $\Gamma$ 上の変位 $\tilde{u}_{i}\left(\omega ; x, k_{y}, z\right)$ と表面力 $\tilde{p}_{i}\left(\omega ; x, k_{y}, z\right)$ を、(1) 式を連立方程式に置換して求める。 $\left(k_{y}\right)$ に関する離散 化波数に関する積分は参考文献 9) の方法を利用する。

2) $\Gamma$ 上の変位 $\tilde{u}_{i}\left(\omega ; x, k_{y}, z\right)$ と表面力 $\tilde{p}_{i}\left(\omega ; x, k_{y}, z\right)$ を用い て任意点（地表面含む）の振動数領域， $k_{y}$ 領域の伝達 関数 $\widetilde{Z}_{i}\left(\omega ; x, k_{y}, z\right)$ を計算する。

3) 各 $k_{y}$ に対する $\widetilde{Z}_{i}\left(\omega ; x, k_{y}, z\right)$ を用いて, 逆フーリ工変換 を行ない振動数領域の伝達関数 $Z_{i}(\omega ; x, y, z)$ を求める。

4) フーリエ変換された入力 $I_{i}(\omega ; x, y, z)$ を用い, 振動数領 域応答 $U_{i}(\omega ; x, y, z)$ を計算する。

$$
U_{i}(\omega ; x, y, z)=Z_{i}(\omega ; x, y, z) \times I_{i}(\omega ; x, y, z)
$$

5) 振動数領域応答 $U_{i}(\omega ; x, y, z)$ を逆フーリエ変換して時 刻歴応答 $u_{i}(t ; x, y, z)$ を計算する。

（1999年 1 月 10 日原稿受理，1999年 8 月 16 日採用決定） 